\title{
Short duration combination chemotherapy in the treatment of small cell lung cancer
}

\author{
A J DORWARD, S W BANHAM, A W HUTCHEON, S AHMEDZAI, \\ D CUNNINGHAM, A GREGOR, M SOUKOP, B H R STACK, N S D MACKAY, \\ S B KAYE
}

From the Departments of Respiratory Medicine and Radiotherapy and the University Department of Medical Oncology, Western Infirmary, Glasgow; the Departments of Respiratory Medicine and Medical Oncology, Royal Infirmary, Glasgow; and the Department of Medical Oncology, Woodend Hospital, Aberdeen

ABSTRACT Ninety five patients (57 with limited disease and 38 with extensive disease) with pre- $\stackrel{\circ}{\rightarrow}$ viously untreated small cell lung cancer were entered into a study of short duration combination SD $^{\circ}$ chemotherapy with intravenous cyclophosphamide $\left(750 \mathrm{mg} / \mathrm{m}^{2}\right)$ on day 1 , adriamycin $\left(40 \mathrm{mg} / \mathrm{m}^{2}\right) \stackrel{\frac{\nabla}{\Phi}}{\frac{O}{\Phi}}$ on day 1 , and etoposide VP-16 $\left(100 \mathrm{mg} / \mathrm{m}^{2}\right)$ on days 1,2 , and 3 , with the addition on day 10 of $\frac{\mathbb{}}{3}$ methotrexate $50 \mathrm{mg} / \mathrm{m}^{2}$ with folinic acid rescue and vincristine $2 \mathrm{mg}$. The treatment was repeated on day 22 and only three courses were given. No maintenance chemotherapy was given, though $\vec{\oplus}$ patients with a complete response received radiotherapy (30-40 Gy (3000-4000 rads)) to the pri- $\infty_{\sigma}^{\infty}$ mary site in most cases. Forty nine patients $(86 \%)$ with limited disease achieved a response, with $26 \%$ $(46 \%)$ complete remissions. Twenty five patients $(66 \%)$ with extensive disease had a response, but only eight $(21 \%)$ had a complete response. Actuarial survival analysis for the whole patient population showed a median survival of 13 months for patients with limited disease and seven months for those with extensive disease. The median survival was 14 months for those patients with limited $\stackrel{\varnothing}{\Phi}$ disease who achieved a complete response, but only 10 months for non-responders. $\overrightarrow{\vec{P}}$ Myelosuppression was the major expression of toxicity. There were three deaths related to $\frac{3}{3}$ treatment and seven patients had febrile episodes during neutropenia that required antibiotics. Mucositis, which was usually mild, occurred in $49 \%$ of patients. The primary site was the main site of initial relapse in $56 \%$ of the patients who relapsed. Among patients with limited disease who achieved a complete response, relapses at the primary site were less common in those who received $\frac{0}{\Omega}$ radiotherapy (five out of 12) than in those who did not (all eight). The results indicate that this short $\stackrel{x}{-}$ duration chemotherapy in small cell lung cancer gives response rates and the potential for long term 3 survival similar to those obtained in other series while allowing patients the maximum time free from treatment.

Small cell carcinoma of the bronchus is a rapidly growing tumour that is often disseminated by the time of diagnosis. ${ }^{1}$ Patients who achieve a complete response to combination chemotherapy have a significant increase in median survival and a chance of becoming long term survivors. ${ }^{2}$ Cohen et $a l^{3}$ have shown that response rates, and thus survival, can be improved by increasing the doses of the drugs given in the initial induction chemotherapy. Dosage, however, is limited by unwanted side effects. One way of reduc-

Address for reprint requests: Dr AJ Dorward, Royal Alexandra Infirmary, Paisley PA2 6LX.

Accepted 25 February 1986

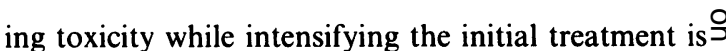
to introduce non-myelosuppressive agents between $\frac{7}{0}$ regular cycles of myelosuppressive drugs. We chose three drugs with a relatively strong myelosuppressive action that are effective in combination in small cell ${ }_{N}$ lung cancer. ${ }^{4}$ Cyclophosphamide, adriamycin, and etoposide were given in maximum tolerated doses in $\mathrm{a}_{\sigma}^{\mathrm{\omega}}$ three weekly cycle; while two effective drugs with relatively little myelotoxic action, methotrexate and vincristine, were given in the middle of the cycle. Chemotherapy was limited to three courses, but a group of responders in the early stages of the study were $\frac{}{0}$ selected for late dose intensification treatment $\frac{\text { }}{\Phi}$ (LDIT), the details of which have been published elsewhere. $^{5}$ 
Table 1 Characteristics of the patients

\begin{tabular}{llc}
\hline & Disease group & \\
\cline { 2 - 3 } & $\begin{array}{l}\text { Limited } \\
(n=57)\end{array}$ & $\begin{array}{c}\text { Extensive } \\
(n=38)\end{array}$ \\
\hline Age (y): median & 60 & 59 \\
range & $(28-70)$ & $(33-70)$ \\
Sex: male & 33 & 26 \\
female & 24 & 12 \\
ECOG performance grade & 25 & 12 \\
0 & 20 & 13 \\
1 & 12 & 13 \\
\hline
\end{tabular}

ECOG-Eastern Cooperative Oncology Group.

\section{Methods and patients}

From June 1982 to January 1984 patients with histologically or cytologically proved small cell lung cancer were entered into the study. Criteria for entry included the presence of measurable or evaluable disease, adequate renal function (creatinine clearance $>60 \mathrm{ml} / \mathrm{min}$ ), and adequate bone marrow reserve (leucocyte count $>3 \times 10^{9} / 1$ and platelets $\left.>100 \times 10^{9} / 1\right)$. Only previously untreated patients aged 70 years or less, with an Eastern Cooperative Oncology Group performance grade of 0,1 , or 2 , were eligible. Evidence of central nervous system metastases excluded patients from the study.

Pretreatment staging included physical examination, full blood count, biochemical tests, chest radiography, fibreoptic bronchoscopy, and radionuclide or ultrasonic scanning of the liver. Patients were categorised as having limited disease (disease confined to one hemithorax but including ipsilateral mediastinal scalene or lower cervical nodes) or extensive disease (spread beyond these limits).

Chemotherapy consisted of cyclophosphamide $750 \mathrm{mg} / \mathrm{m}^{2}$ on day 1 (except in the first 15 patients, who had $1000 \mathrm{mg} / \mathrm{m}^{2}$ ), adriamycin $40 \mathrm{mg} / \mathrm{m}^{2}$ on day 1 , and etoposide $100 \mathrm{mg} / \mathrm{m}^{2}$ on days $1-3$. On day 10 methotrexate $50 \mathrm{mg} / \mathrm{m}^{2}$ and vincristine $2 \mathrm{mg}$ were given. Oral folinic acid in a dose of $15 \mathrm{mg}$ four times daily for three days was started 24 hours after the methotrexate. If the leucocyte count was less than $1 \times 10^{9} / 1$ on day 10 , treatment was delayed. The treatment was repeated on day 22. Appropriate dose reductions were made in cyclophosphamide and adriamycin for myelosuppression and in methotrexate for mucositis during the next cycle.

After three courses of treatment patients were reassessed. A complete response was defined as disappearance of all known disease for at least four weeks as judged by physical examination, radiology, and bronchoscopy. A partial response was taken as a $50 \%$ or greater reduction in total tumour size without progression at other sites or the appearance of new lesions. No response indicated less than $50 \%$ tumour reduction, with stable or progressive disease. In two centres patients who had a complete response then received radiotherapy $(30-40$ Gy $(3000-4000$ rads $)$ over 19 days) to encompass the primary and nodal sites of disease, but this was omitted in a third centre. No further treatment was given to patients except on a symptomatic basis. Twenty two responding patients with a good partial or complete response were selected on a non-randomised basis in the first six months of the study to receive late dose intensification therapy with high dose cyclophosphamide and etoposide with autologous bone marrow rescue. As this may have biased results, these patients have been excluded from the analysis of data on survival.

Survival was recorded from the first day of treatment. Assessment of survival was by life table methods, the log rank test being used.

\section{Results}

A total of 95 patients entered the study. Of these, 57 had limited and 38 extensive disease. Their characteristics are given in table 1 . Six patients discontinued treatment after one course and two did so after two courses because of rapid deterioration or death. These patients have not been excluded from the overall analysis.

Forty nine $(86 \%)$ of the 57 patients with limited

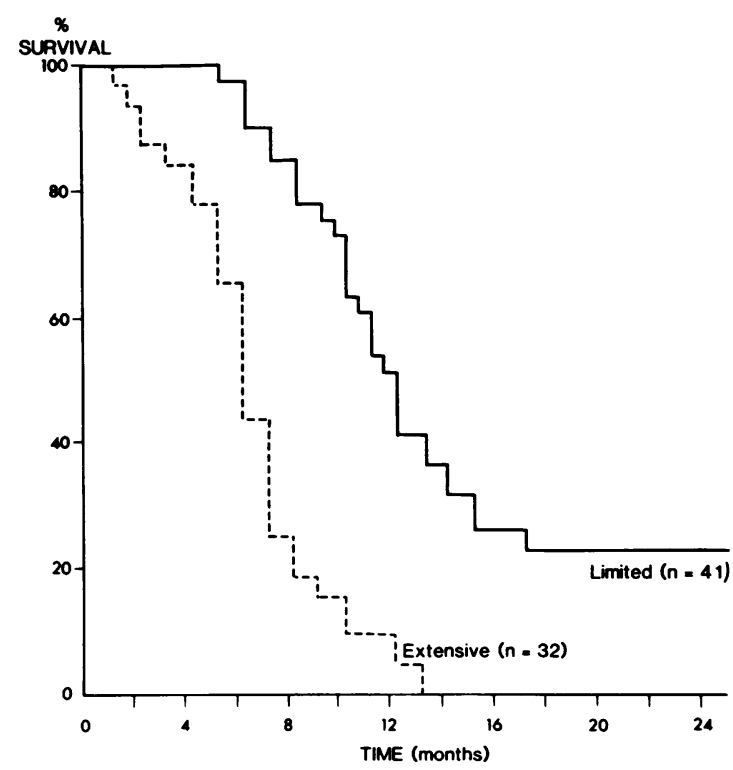

Fig 1 Actuarial survival curves for limited and extensive disease. Patients who received late dose intensification treatment have been excluded. 


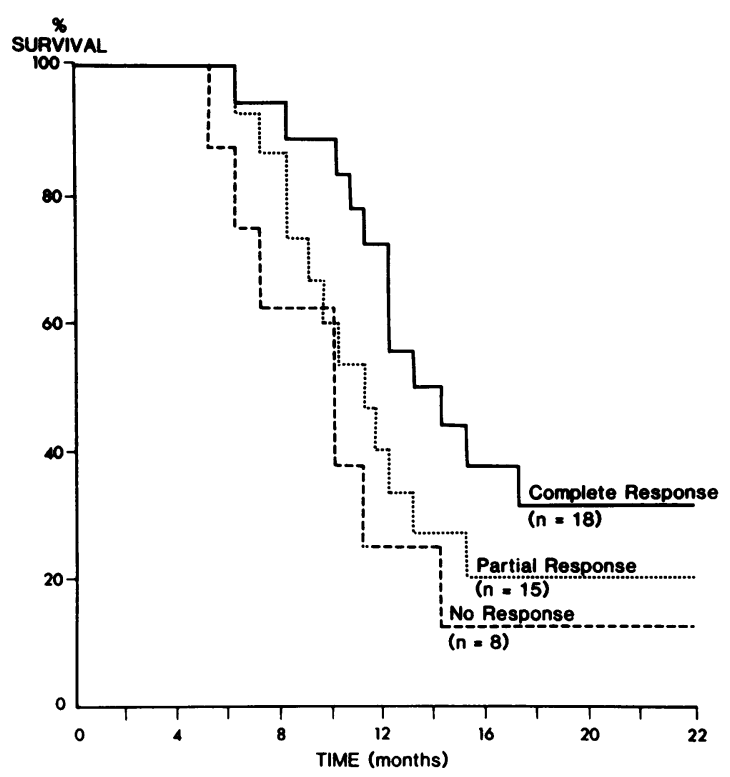

Fig 2 Survival curves for patients with limited disease grouped by response to initial chemotherapy.

disease achieved a response; in $26(46 \%)$ this was a complete remission. Of 38 patients with extensive disease, only eight $(21 \%)$ achieved complete response, with $25(66 \%)$ responding overall.

Patients have been followed up for 14-32 months. All patients with extensive disease have died. Thirteen patients with limited disease are still alive; eight of these had a complete response and four a partial response. Figure 1 shows the actuarial survival curve for those with limited and extensive disease, excluding those who received late dose intensification treatment. The median survival for limited disease is 13 months and for extensive disease seven months $(\mathrm{p}<$ 0.001 ). Figure 2 shows the survival curves for responders and non-responders with limited disease. Median survival correlated with response and was 14 months for patients with limited disease who achieved a complete response, but only 10 months for nonresponders $(p=0.04)$. The two year projected survival for complete responders who had limited disease is $32 \%$. Of the 26 patients who had a complete response, eight are still alive, seven of them more than 20 months from the start of treatment, and six are in remission.

Table 2 shows the median survival and numbers of patients with limited disease who did and did not receive late dose intensification treatment. This table and the actuarial survival analysis indicate that this treatment did not confer any survival benefit after induction chemotherapy. The full results have been published elsewhere. $^{5}$
Most patients experienced nausea and some vom- $\stackrel{\overrightarrow{\vec{S}}}{\rightarrow}$ iting on the first day of chemotherapy. Leucopenia 0 was the major haematological toxic effect, $18 \%$ hav- 을 ing a leucocyte nadir below $0.5 \times 10^{9} / 1$. This occurred $\frac{\bar{\sigma}}{\bar{\sigma}}$ mainly around day 10 during the first course of treat- $\stackrel{\varnothing}{\varrho}$ ment. Haematological toxicity was greater with the higher dose of cyclophosphamide and the dose was later reduced to $750 \mathrm{mg} / \mathrm{m}^{2}$. There were three deaths $\vec{\circ}$ related to treatment, which occurred about the time $\overrightarrow{\vec{\omega}}$ of maximum myelosuppression. The platelet count $\stackrel{\circ}{\circ}$ was seldom seriously reduced and no bleeding epi- $\vec{x}$ sodes occurred. Mucositis, usually after the metho- $\stackrel{x}{+}$ trexate given on day 10 , was common but seldom $\overrightarrow{0}$ posed a serious problem.

Forty patients out of 49 responders with limited $\stackrel{\infty}{\infty}$ disease have relapsed. The primary site was the most $ᄋ$ frequent initial site of relapse $(56 \%)$, brain $(36 \%)$ and bone $(36 \%)$ being the next most common sites with $\omega$ clinically detectable tumours. In the group with lim- $\frac{\mathbb{D}}{0}$ ited disease 16 of the patients with a complete $\frac{\mathbb{\mathbb { D }}}{3}$ response were given radiotherapy to the primary site after chemotherapy; and only five out of the 12 who $\stackrel{\mathbb{S}}{-}$ relapsed did so because of recurrence at the primary $\vec{\bullet}$ site. Eight of the 10 patients with a complete response $\stackrel{\infty}{\circ}$ who were not given radiotherapy have relapsed, all 0 initially with recurrences at the primary site. Eighteen patients had palliative radiotherapy to various sites on relapse.

\section{Discussion}

This five drug regimen is highly active against small cell bronchial carcinoma. The chemotherapy differs from other schedules in two respects. The first is that the treatment lasted no longer than nine weeks, and no maintenance treatment was given. The $46 \%$ complete response rate in limited disease and the survival data are similar to the results obtained in other series. $^{6-10}$ Analysis of actuarial survival projects a two year survival of $20 \%$ in patients with limited disease, which is similar to that reported with more 0 prolonged chemotherapy. ${ }^{6-10}$ Aisner et $a l^{4}$ used adriamycin, cyclophosphamide, and etoposide in similar dosages to ours as induction treatment, fol-

Table 2 Patients with limited disease: median survival in those who did and did not receive late dosage intensification treatment (LDIT)

\begin{tabular}{llll}
\hline & \multicolumn{4}{l}{ Median survival in months (total numbers) } \\
\cline { 2 - 4 } & $C R$ & $P R$ & $N R$ \\
\hline $\begin{array}{l}\text { All patients } \\
\text { With LDIT }\end{array}$ & $14(26)$ & $11(23)$ & $10(8)$ \\
Without LDIT & $14(18)$ & $12(8)$ & $(11(15)$ \\
\hline
\end{tabular}

$\mathrm{CR}$-complete response; $\mathrm{PR}$ - partial response; $\mathrm{NR}-$ no response 
lowed by various additional drugs, and their response rates were higher than in this series. The patients are not, however, strictly comparable, as we adopted a simpler staging procedure, so that our patients with "limited" disease were not so highly selected.

The second difference between this schedule and previously reported treatment is the addition of methotrexate and vincristine on day 10 of the cycle, at the time of appreciable myelosuppression. This approach has proved successful in non-Hodgkin's lymphoma, ${ }^{11}$ but its value in small cell lung cancer remains unproved. Previous studies in which methotrexate has been added in midcycle have yielded similar response rates. ${ }^{7}$ If further use of this five drug schedule is contemplated a randomised study to assess the value of the treatment on day 10 would be appropriate.

The usefulness of thoracic radiotherapy in addition to chemotherapy for small cell lung cancer remains controversial. ${ }^{12}{ }^{13} \mathrm{It}$ appears to reduce or delay recurrence at the primary site but does not alter median survival. ${ }^{9}$ In view of this we gave radiotherapy only to those patients who had achieved a complete response to initial treatment, and one centre elected not to give radiotherapy routinely.

The results of our study indicate that a nine week course of combination chemotherapy in the treatment of small cell lung cancer gives response rates and long term survival figures similar to those achieved with more prolonged chemotherapy. This is in agreement with recent reports suggesting that long term maintenance chemotherapy may be ineffective. ${ }^{81014}$ One aim of future studies could therefore be an analysis on a randomised basis of the optimal duration of treatment that would yield a satisfactory complete response rate but allow the patients the maximum time possible free from treatment.

We are grateful to Mr David Hole of the West of Scotland Cancer Surveillance Unit for statistical help and Miss E Sharkie for secretarial assistance.

\section{References}

1 Greco FA, Einhorn LH, Richardson RL, Oldham RK. Small cell lung cancer: progress and perspectives.
Semin Oncol 1978;5:323-33.

2 Greco FA, Richardson RL, Snell JD, et al. Small cell lung cancer. Complete remission and improved survival. Am J Med 1979;66:625-30.

3 Cohen MH, Greaven PJ, Fossieck BE, et al. Intensive chemotherapy of small cell bronchogenic carcinoma. Cancer Treat Rep 1977;61:349-54.

4 Aisner J, Whitacre M, VanEcho DA, Wesley M. Wiernik PN. Doxorubicin, cyclophosphamide and VP16-213 (ACE) in the treatment of small cell lung cancer. Cancer Chemother Pharmacol 1982;7:187-93.

5 Banham S, Soukop M, Ahmedzai S, et al. Late dose intensification chemotherapy in small cell lung cancer. In: McVie JG, Dalesio O, Smith IE, eds. Autologous bone marrow transplantation and solid tumours. New York: Raven Press, 1984:105-10.

6 Harper PG, Souhami RL, Spiro SG, et al. Tumour size, response rate and prognosis in small cell carcinoma of the bronchus treated by combination chemotherapy. Cancer Treat Rep 1982;66:463-70.

7 Arnold AM, Williams CJ, Mead GM, et al. Combination chemotherapy using high or low dose methotrexate for small cell carcinoma of the lung - a randomised trial. Med Oncol Tumour Pharmacother 1984;1:9-14.

8 Thatcher N, Hunter RD, Jegarajah S, et al. Eleven week course of sequential methotrexate, thoracic irradiation and moderate-dose cyclophosphamide for "limited" small cell bronchogenic carcinoma. Lancet 1982;i: 1040-3.

9 Souhami RL, Geddes DM, Spiro SG, et al. Radiotherapy in small cell lung cancer treated with combination chemotherapy: a controlled trial. $\mathrm{Br} \mathrm{Med} J$ 1984;228:1643-6.

10 Feld R, Evans WK, De Boar G, et al. Combined modality induction therapy without maintenance chemotherapy for small cell carcinoma of the lung. $J$ Clin Oncol 1984;2:294-304.

11 Skarin AT, Canellos GP, Rosenthal DS, et al. Improved prognosis in diffuse histiocytic and undifferentiated lymphoma by use of high-dose methotrexate alternating with standard agents (M-BACOD). J Clin Oncol 1983;1:91-5.

12 Cohen MH. Is thoracic irradiation necessary for patients with limited-stage small cell lung cancer? No. Cancer Treat Rep 1983;67:217-21.

13 Byhardt RW, Cox JD. Is chest radiotherapy necessary in any or all patients with small cell carcinoma of the lung? Yes. Cancer Treat Rep 1983;67:209-15.

14 Smith IE, Sappino AP, Bondy PK, et al. Long term survival five years or more after combination chemotherapy and radiotherapy for small cell lung cancer. Eur J Cancer Oncol 1981;17:1249-53. 